\title{
Total lymphoid irradiation in multiple sclerosis
}

C M Wiles, L Omar, A V Swan, G Sawle, J Frankel, R Grunewald, T Joannides, P Jones, H Laing, P H Richardson, A S Hamblin, J Harris, G Thomas, D H Miller, I F Moseley, W I MCDonald, D G MacManus

Abstract

Following a report of the efficacy of total lymphoid irradiation (TLI) in the treatment of chronic progressive multiple sclerosis a further randomised doubleblind placebo-controlled study was undertaken with the intention of entering 56 patients. In the event it was possible to recruit only 27 patients in a 2.5 year period. Three patients received active treatment openly and 24 were randomised to either active (14) or sham (10) treatment. Treatment was 1980 cGy to the lymphoid system and spleen or sham treatment after full simulation. The primary outcome measure was a comparison of the mean rates of change between treatment groups on the expanded Kurtzke disability scale (EDSS) over the two year follow up period. Patients were also assessed on other clinical outcome measures, psychometry, and serial MRI of the brain. Active treatment resulted in a profound and prolonged fall in $T$ lymphocytes especially those with the CD4 marker and a reversal in CD4:CD8 ratio. No significant benefit was demonstrated on the rate of clinical disease progression (EDSS). A small but significant benefit was found on a score of bladder function. No significant benefit was demonstrated on other clinical or psychometric indices or on subjective visual analogue scales. There was a small but significant difference in the rate of accumulation of lesions on brain MRI favouring the treatment group. The treated group had a higher incidence of clinically relevant side effects, notably amenorrhoea and infections: three deaths (one in the TLI group, two in the sham treated group) occurred. A post hoc calculation indicates that the study had a possible $35 \%$ risk of a false negative result using the principal outcome measure. The study fails to confirm the previously reported clinical benefit of TLI although there may be a minor benefit on disease progression as indicated by MRI lesion counts. It is concluded that TLI cannot be recommended for the routine treatment of chronic progressive multiple sclerosis but the beneficial effect on MRI lesions, though modest, suggests that further research into immune modulation of this condition may be worthwhile.

(F Neurol Neurosurg Psychiatry 1994;57:154-163)
Multiple sclerosis is an inflammatory disease of the CNS in which there is episodic impairment of the blood brain barrier, perivascular inflammation, and demyelination: it is thought that immunoregulatory defects, especially in $\mathrm{T}$ cell function, play an important part in pathogenesis. ${ }^{1-3}$ In recent years there have been several controlled and blinded trials of therapy that have attempted to modulate or suppress immune mechanisms to alter the clinical course of multiple sclero$\operatorname{sis}^{4-10}$ with modest or no benefits and, often, clinically relevant side effects. The high sensitivity of lymphocyte populations to ionising radiation $^{11}$ has led to the use of total lymphoid irradiation (TLI) in some non-malignant diseases thought to have an immune basis. These include rheumatoid arthritis ${ }^{12-15}$ and lupus nephritis. ${ }^{16}$ TLI has also been used in preparatory treatment for organ transplantation. ${ }^{17}$ There is evidence of potent and prolonged effects of TLI on circulating populations of lymphocytes and some evidence of clinical efficacy. Preliminary ${ }^{18}$ and later definitive ${ }^{19}$ results in chronic progressive multiple sclerosis showed some benefit from TLI (1980 cGy) compared with sham treatment in a double-blind study on 40 patients based on a single functional scale combining ordinal measures of gait, activities of daily living, and transfer ability but without clear benefit on a modified disability scale. Early side effects were few but subsequently a number of late deaths occurred in the treated group. ${ }^{20}$ In 1987 we commenced a further double-blind trial of TLI in chronic progressive multiple sclerosis with a similar treatment protocol: a preliminary account of the study was presented to the Association of British Neurologists in April 1990. ${ }^{21}$

\section{Methods}

PATIENTS

All patients had clinically definite or laboratory supported definite multiple sclerosis ${ }^{22}$ and were classified as having relapsing remitting progressive or primary progressive multiple sclerosis before entry to the trial. Patients were recruited to the study through the neurological clinics at St Thomas's Hospital and the National Hospitals for Neurology and Neurosurgery and by writing to neurologists in London about the proposed study. The patient's general practitioner was kept fully informed. To be eligible patients had to be aged 20 to 60 years, have documented evidence of progression of disability of one full grade on the Kurtzke expanded disability 
status scale (EDSS) in the preceding year, to score at $\leqslant 6.5$ on the scale at the time of recruitment, to be able to attend St Thomas' Hospital and the National Hospital regularly, and to give informed consent. Exclusion criteria were severe psychiatric disorder or cognitive impairment sufficient to preclude informed consent, evidence of chronic infection, lung disease, other serious medical disorder or previous neoplasm, leucopenia $<4.5 \times 10^{9} / 1$, platelet count $<100 \times 10^{9}$ or anaemia, previous immunosuppressive medication (other than corticosteroids), pregnancy or the desire (by either partner) for future pregnancy, and inadequate social support at home. Patients were provided with an information sheet about the trial. After clinical assessment the trial was discussed in detail normally together with a close relative or carer: special attention was paid to counselling those female patients who were premenopausal about the likelihood of amenorrhoea. Written consent for the study was obtained at a subsequent separate visit to the clinic or an admission before the start of the trial. The trial received ethical approval from the West Lambeth Health Authority Ethics Committee.

\section{PATIENT NUMBER}

It was our intention to randomise 56 patients to this study: this was based on detecting a mean difference between the treated and control groups of 0.7 (SD 1.34) points on the $\mathrm{EDSS}^{4}$ over a year $(a 0.05$, power 0.8$)$. In the event enough suitable patients could not be recruited in a reasonable time. Over a two year period 66 patients were referred as fulfilling the trial criteria of whom 15 were unsuitable for various reasons (age, lack of documented progression, concomitant or previous general medical disorder) and 24 otherwise suitable patients declined entry after information and counselling. Three patients were not randomised and were treated with TLI openly but had assessments performed blind: they included the first two patients with multiple sclerosis treated with TLI by us and one patient who had agreed to trial entry but subsequently became incompetent to give consent due to severe and rapidly progressive multiple sclerosis and was given active treatment. Twenty four patients were randomly allocated to treatment with TLI or sham treatment.

\section{TREATMENT TECHNIQUE}

Lung function (vital capacity and peak flow rate), chest radiograph, electrocardiogram, abdominal ultrasound to localise kidneys and spleen, serum biochemistry, thyroid function test, and full blood count were undertaken before radiotherapy planning. Treatment for all patients was planned on a simulator in the prone and supine position with hands on hips. The modified mantle field extended from the top of the thyroid cartilage to the lower border of the first lumbar vertebra to include the spleen as localised by ultrasound. The inverted $Y$ field extended from the mid- dle of the second lumbar vertebra to the lower border of the obturator foramina with central pelvic shielding. Other areas of shielding included a midline spinal block posteriorly and anterior thyroid block from the beginning of treatment. A $2 \mathrm{~cm}$ spinal block was also used at the superior border of the inverted $\mathrm{Y}$ field to avoid the possibility of excessive doses to the spinal cord at this point as well as a radiological gap equal to the length of half a vertebra at the junction of the mantle and inverted $\mathrm{Y}$ field. Initially, custom made lung blocks (Cerrobend) were used equivalent to 3.5 half value layers $(12.5 \%$ transmission), but after the first six patients, these blocks were reused for subsequent patients, with templates to obtain an optimum fit for each patient. Only after full simulation, including field verification, were the patients randomised to active or sham treatment.

Treatment was on a Philips SL75-10 $8 \mathrm{MeV}$ linear accelerator using photon beam. Patients were treated with anterior and posterior treatment fields to a total midline dose of $1980 \mathrm{cGy}$ in 12 fractions over 16-18 days first to the mantle and then to the inverted $Y$ field, with treatment five days a week. Treatment was on average over 37 days, the mantle and inverted $\mathrm{Y}$ field treated in sequence with no break. The estimated dose to the spinal cord was an average of $64 \%$ maximum and to the brain $\leqslant 3 \%$. Sham irradiation was given in an identical manner apart from the use of a square pulse generator plus amplifier to simulate the noise normally emitted by the linear accelerator. During treatment patients had a full blood count weekly for the first two weeks, twice a week for the remaining period of treatment, monthly for the next six months, and every three months up to two years. Serum biochemistry was repeated at the end of treatment, thyroid function at six months after treatment, and lung function tests at one and three months after treatment. A questionnaire about the side effects of treatment was presented after the treatment period and patients were asked at the six month follow up visit which treatment modality (active or sham) they thought that they had received.

\section{ASSESSMENTS}

\section{Clinical}

All patients had the following clinical assessments undertaken before and every six months after completion of TLI or sham treatment up to 24 months: functional systems score and EDSS, ${ }^{23}$ the "functional scale" used by Cook et al in the previous trial of lymphoid irradiation, ${ }^{19}$ a timed walk, and a series of visual analogue scales for gait, upper limb function, vision, and bladder function scored by the patient. The incapacity status scale and a slightly modified version of the environmental status scale $^{24}$ were rated, usually in the presence of a relative or carer, before and annually after treatment. Assessments were undertaken by a physician who was blind to the patient's treatment and 
who was uninvolved with their medical management. At the end of the initial 24 month follow up period patients and their general practitioners were contacted annually by letter. Patients have also been flagged in the National Health Service Central Register for death notification and cancer registration.

\section{Analysis of clinical data}

Where the assumption of a normal distribution for the clinical outcome measures was appropriate, analyses were performed by two group comparison $t$ tests. As subjects were assessed on several occasions over a period of time, a more sensitive assessment of the treatment effect may be obtained by investigating the pattern of change in the outcome measures. To do this, trends in disability scores and other measures of outcome were identified for each patient and the gradients of those trends were compared between treatment and control groups. Regression methods were used to make this comparison allowing for the possible effects of age, sex, and pattern of initial disease. Analyses were made with GLIM. ${ }^{25}$

\section{Psychometry}

Psychometric assessments were undertaken before treatment, and at one and two years of follow up. Testing time was limited to 60 minutes because of fatigue and the fact that other assessments had to be undertaken on the same day: tests requiring recognition of fine visual detail were excluded. The following tests were undertaken: the National adult reading test and Schonell reading test, ${ }^{26}$ four subscales (arithmetic, similarities, digit span, and vocabulary) of the Wechsler adult intelligence scales (WAIS), three Willison speed tasks (counting letters, counting backwards, and reading numbers out loud from a card), ${ }^{27}$ modified recognition memory tests, ${ }^{28}$ Raven progressive matrices, ${ }^{29}$ and the modified Wisconsin card sorting test. ${ }^{30}$ Not all patients were able to complete the assessments at follow up and complete data sets were obtained on 11 treated and five sham treated patients. Data on each outcome measure were examined for outlying scores and for normality of distribution. Square root or log transformations were used for some significantly skewed variables. Changes in score over time were examined with repeated measures analysis of variance.

\section{MRI}

Magnetic resonance imaging of the brain was performed on all patients before treatment and at intervals of six months after treatment, with a $0.5 \mathrm{~T}$ Picker superconducting system provided by the Multiple Sclerosis Society of Great Britain and Northern Ireland. On each occasion, $5 \mathrm{~mm}$ thick contiguous axial slices were obtained through the whole brain by means of a T2 weighted sequence $\left(\mathrm{SE}_{2000 / 60}\right)$ with a $30 \mathrm{~cm}$ field of view, a $256 \times 256$ matrix, and two averages. The scanning plane was determined by four oblique pilots (axial, coronal, sagittal, and a final check axial pilot) to ensure consistency of the imaging plane throughout the study. In previous studies, ${ }^{31}$ repositioning has been shown to be better than $\pm 4^{\circ}$ : this has been improved further by the current method, thus facilitating comparison between serial images. ${ }^{32}$

All images were viewed and scored by an experienced neuroradiologist (IFM) who was unaware of the patients' treatment. To calculate the total lesion load on the baseline MRI, the brain was divided into 15 anatomical regions and the number and size of each lesion was recorded. Lesion size was scored as: $<5 \mathrm{~mm}$ in the largest diameter 1 point; 5-10 mm 2 points; $>10 \mathrm{~mm} 3$ points. An extra point was scored if a lesion displayed confluence. At follow up studies (six, 12, 18, and 24 months) changes from the previous images were recorded as: new lesions, enlarging lesions, lesions showing a reduction in size, and lesions that had disappeared altogether. In the analysis new and enlarged lesions were summed as were lesions that became smaller or disappeared. Gadolinium DTPA was not systematically used as a contrast agent in this study as it was not generally available when the study began but it was administered on at least one occasion to 13 patients.

\section{Blood and lymphocyte subset counts}

Routine blood counts during and after treatment were undertaken on a Coulter counter. Venous blood samples were taken before treatment, on days 9 and 19 of treatment, and at intervals of three months afterwards for up to two years. Mononuclear cells were isolated from whole blood by buoyant density centrifugation. Cells were labelled with a range of directly conjugated monoclonal antibodies (Becton-Dickinson Ltd) and the proportion of fluorescent cells was measured by flow cytometry (FACScan, Becton Dickinson Ltd). Absolute numbers of fluorescent lymphocytes were determined from the haematological lymphocyte count.

\section{Results}

Twenty-seven patients were entered into the study, three of whom were treated openly but had blinded assessments of their MRI images and physical state. Of the remainder, 14 were randomised to TLI and 10 to sham TLI. Table 1 shows the clinical details together with the initial lesion load on MRI.

Differences between the treatment groups for sex distribution, disability, or lesion load on MRI scan were small. The sham treated group had had multiple sclerosis for slightly longer, and had fewer patients with primary progressive disease (1/10 compared with $5 / 17$ in active group). This potentially important factor of different numbers of such patients is taken into account in the analysis. Patients treated with TLI had on average received a course of steroids more recently than the sham group.

All patients had a full course of TLI or sham treatment apart from one who devel- 
Table 1 Pretreatment variables

\begin{tabular}{|c|c|c|c|}
\hline & \multicolumn{3}{|l|}{ Treatment group } \\
\hline & Treated (all) & $\begin{array}{l}\text { Treated } \\
\text { (randomised) }\end{array}$ & Sham \\
\hline $\begin{array}{l}\text { No } \\
\text { Age (y) } \\
\text { Men } \\
\text { Relapse progressive } \\
\text { Duration of multiple sclerosis (y) } \\
\text { Last steroids (y) } \\
\text { EDSS one year before entry } \\
\text { EDSS at entry }\end{array}$ & $\begin{array}{l}17 \\
36 \cdot 6(7 \cdot 9) \\
9 \\
12 \\
5 \cdot 79(4 \cdot 10) \\
0 \cdot 68(0 \cdot 82) \\
4 \cdot 38(1 \cdot 52) \\
6 \cdot 15(1 \cdot 01)\end{array}$ & $\begin{array}{l}14 \\
38 \cdot 1(7 \cdot 8) \\
8 \\
9 \\
6 \cdot 36(4 \cdot 12) \\
0 \cdot 83(0 \cdot 87) \\
4 \cdot 50(1 \cdot 32) \\
6 \cdot 11(1 \cdot 00)\end{array}$ & $\begin{array}{l}10 \\
39 \cdot 1(3 \cdot 3) \\
7 \\
9 \\
9 \cdot 78(5 \cdot 92) \\
3 \cdot 03(4 \cdot 43) \\
4 \cdot 25(1 \cdot 51) \\
5 \cdot 45(1 \cdot 19)\end{array}$ \\
\hline $\begin{array}{l}\text { Change in EDSS in year } \\
\text { before entry } \\
\text { MRI lesion load }\end{array}$ & $\begin{array}{l}-1.77(1.29) \\
105.6(53.0)\end{array}$ & $\begin{array}{c}-1.61(1.27) \\
95.4(43.2)\end{array}$ & $\begin{array}{l}-1.20(1.46) \\
84.0(33.5)\end{array}$ \\
\hline
\end{tabular}

Variables at trial entry are number or mean (SD).

oped hepatitis during the mantle field therapy necessitating discontinuation of treatment at that stage. This was possibly related to coincidental commencement of baclofen just before the treatment started. This patient is included in the analysis. One patient in the sham treated group died suddenly 0.26 years after completion of treatment. A coroner's post mortem examination gave respiratory failure due to multiple sclerosis as the cause of death. A second patient in the sham treated group died of pneumonia and multiple sclerosis 2.9 years after completing treatment. One patient in the TLI group died of left ventricular failure secondary to ischaemic heart disease 2.8 years after the end of therapy. These two patients underwent the full protocol up to two years.

At the time of preparation of the final manuscript the median follow up period for the 24 surviving patients was 4.04 years (range $2 \cdot 20-5 \cdot 92$ years). At clinical data analysis in Oct 1991 all patients had had six and 12 month assessments (apart from one who had died); 25 (93\%) had had an 18 month assessment (one patient did not attend); 21 (78\%) had had a two year assessment; three were not due; and two (different from the two at 18 months) could not attend: for both of these information was subsequently obtained by letter from the general practitioner. Results have been assessed on an intention to treat basis. All the clinical assessment scores after treatment in the patient who died within two years' follow up have been set at the maximum in those scales not specifically scoring death and are included in the analysis unless otherwise stated. At six months of follow up patients were asked whether they considered that they had received TLI or sham treatment: 11 out of 14 patients randomised to TLI believed they had had active treatment including six women all of whom had developed amenorrhoea; five out of nine patients receiving sham treatment (one had died) thought that they had received active treatment $\left(\chi^{2}=0.50, p=0.447\right)$. During the follow up period so far seven out of 17 patients given TLI (five out of 14 randomised) have received further courses of steroid drugs compared with six out of 10 in the sham treated group. One patient in the TLI group subsequently had a thalamotomy for intractable

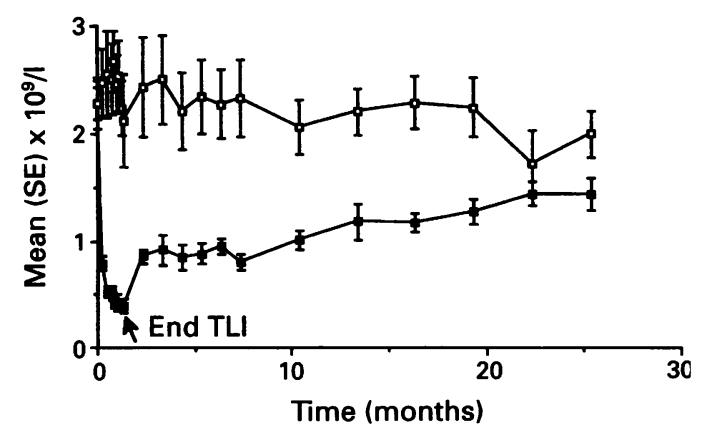

Figure 1 Mean (SE) total lymphocyte counts in the TLI (filled symbols) and sham treated (open symbols) groups before, during, and after treatment. Time zero is at the pretreatment lymphocyte count undertaken on the day before starting treatment.

tremor and one patient in the sham group elected to have TLI elsewhere, both having completed the two year initial follow up period.

\section{BLOOD COUNTS}

Lymphoid irradiation resulted in a profound fall in peripheral blood lymphocyte count (fig 1) that reached a nadir at the end of the treatment course and then gradually recovered over the next two years but remained significantly lower than sham treated patients throughout. Five out of 17 treated patients developed a neutrophil count $<1.0 \times 10^{9} / 1$,
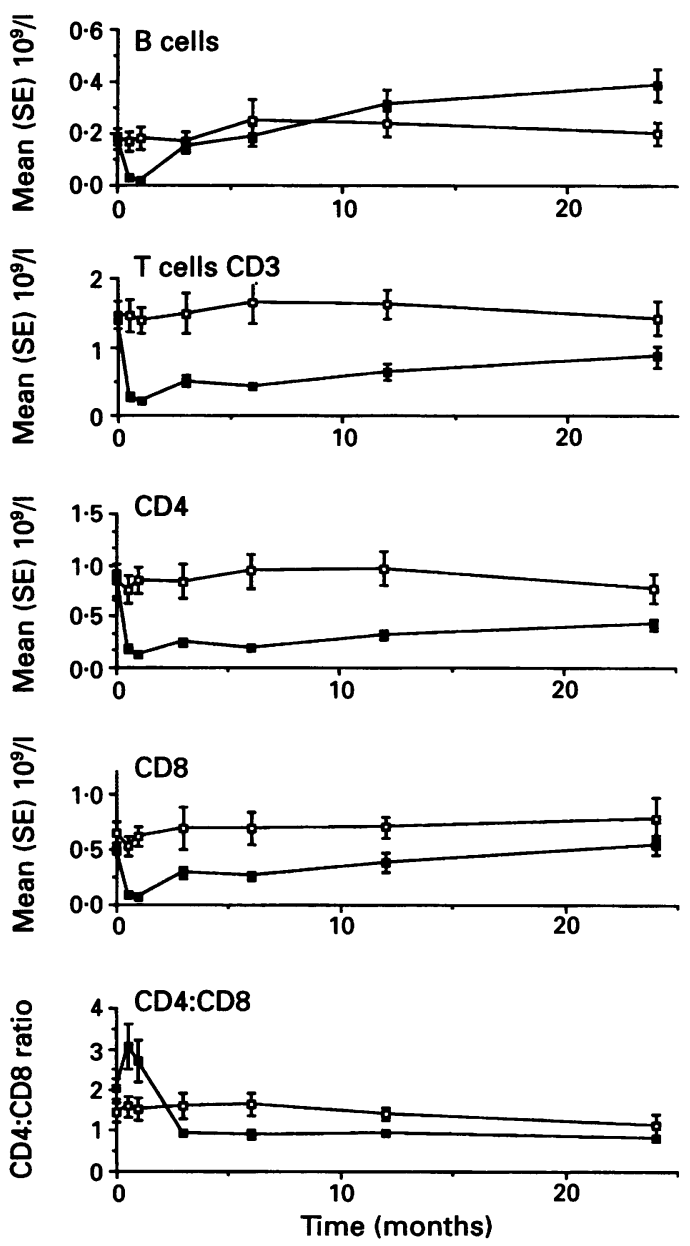

Figure 2 Mean (SE) lymphocyte subsets $B, C D 3, C D 4$, $C D 8$, and CD4:CD8 ratio in the TLI (filled symbols) and sham treated (open symbols) groups before and after treatment. 
Figure 3 Mean (SE) expanded Kurtzke disability status scores. (a) and functional scores (b) for TLI (filled symbols) and sham treated (open symbols) groups about one year before treatment, before, and up to two years after treatment.
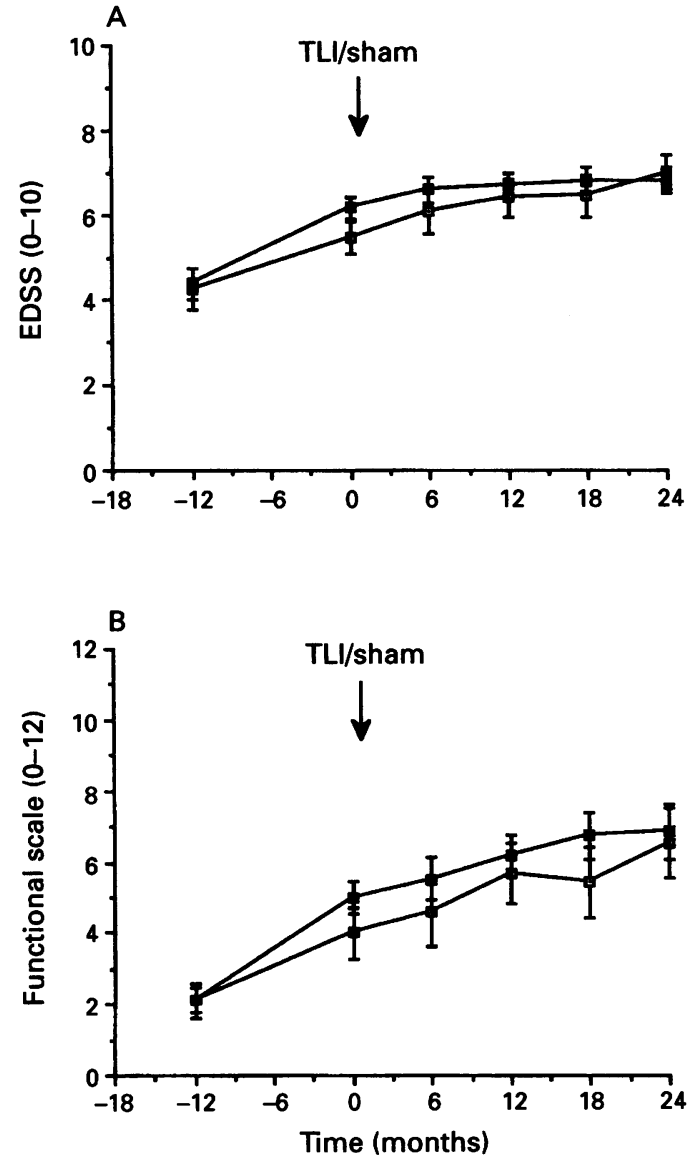

four out of 17 had a decline in haemoglobin concentration $>2 \mathrm{~g} / \mathrm{dl}$, and two out of 17 patients had platelet counts $<100 \times 10^{9} / 1$ during the treatment phase. These indices had returned to normal in all but one patient by the two month follow up.

$T$ cells, particularly those expressing CD4, were profoundly depressed during and after treatment with TLI with gradual but incomplete recovery over the two year follow up period. By contrast there was a rapid partial recovery in CD8 cells in the three months after completion of therapy. Incomplete recovery of CD4 $\mathrm{T}$ cells resulted in a reversal of the CD4:CD8 ratio (fig 2), which lasted from three months to the end of follow up. B cell numbers were initially depressed by therapy but had recovered by three month follow up.

Table 2 Clinical outcome data

\begin{tabular}{|c|c|c|c|c|c|c|}
\hline \multirow[b]{2}{*}{ Outcome } & \multicolumn{3}{|c|}{$T L I$ (all) minus sham } & \multicolumn{3}{|c|}{$T L I$ (randomised) minus sham } \\
\hline & Mean (SE) & $95 \% C I$ & & Mean (SE) & $95 \% C I$ & \\
\hline $\begin{array}{l}\text { EDSS }(0-10) \\
\text { Functional (0-12) } \\
\text { IncSS }(0-64) \\
\text { EnvSS (0-24) } \\
\text { Walk speed (m/s) } \\
\text { FSS-pyramidal (0-6) } \\
\text { FSS-cerebellar (0-5) } \\
\text { FSS - brainstem (0-5) } \\
\text { FSS-visual (0-5) } \\
\text { FSS-sensory (0-5) } \\
\text { FSS - bladder (0-5) }\end{array}$ & $\begin{array}{r}-0.25(0.27) \\
0.06(0.60) \\
-1.13(3.18) \\
0.57(2.13) \\
0.04(0.05) \\
-0.07(0.21) \\
-0.03(0.28) \\
-0.35(0.40) \\
-0.84(0.44) \\
-0.14(0.35) \\
-0.66(0.30)^{\star}\end{array}$ & $\begin{array}{l}-0.81 \text { to } \\
-1.19 \text { to } \\
-7.75 \text { to } \\
-3.85 \text { to } \\
-0.07 \text { to } \\
-0.51 \text { to } \\
-0.61 \text { to } \\
-1.18 \text { to } \\
-1.75 \text { to } \\
-0.86 \text { to } \\
-1.28 \text { to }\end{array}$ & $\begin{array}{l}0 \cdot 30 \\
1 \cdot 32 \\
5 \cdot 49 \\
4.99 \\
0 \cdot 14 \\
0 \cdot 36 \\
0 \cdot 54 \\
0 \cdot 48 \\
0 \cdot 08 \\
0 \cdot 59 \\
-0 \cdot 03\end{array}$ & $\begin{array}{r}-0.26(0.27) \\
0.03(0.56) \\
-1.52(2.57) \\
0.18(1.79) \\
0.04(0.05) \\
-0.08(0.19) \\
-0.07(0.25) \\
-0.32(0.42) \\
-0.87(0.43) \\
-0.11(0.36) \\
-0.66(0.25)^{\star}\end{array}$ & $\begin{array}{l}-0.84 \text { to } \\
-1.15 \text { to } \\
-6.92 \text { to } \\
-3.58 \text { to } \\
-0.07 \text { to } \\
-0.47 \text { to } \\
-0.60 \text { to } \\
-1.21 \text { to } \\
-1.76 \text { to } \\
-0.86 \text { to } \\
-1.19 \text { to }\end{array}$ & $\begin{array}{l}0.31 \\
1.21 \\
3.88 \\
3.93 \\
0.14 \\
0.32 \\
0.45 \\
0.57 \\
0.03 \\
0.65 \\
-0.12\end{array}$ \\
\hline
\end{tabular}

$\star^{\mathrm{p}}<0.05$.

${ }^{\star} \mathrm{p}<0.05$. period between all treated $(n=17)$, or randomised treated $(n=14)$ and sham $(n=10)$ groups; IncSS = incapacity status score; EnvSS = environmental status score; FSS functional system score.

CLINICAL ASSESSMENTS

Figure 3 shows the mean (SE) Kurtzke disability status scores and functional scores of the TLI and sham treated groups before and after treatment. These did not differ. Table 2 shows the differences in the mean rates of change of the major clinical assessments over the follow up period. The comparisons have been made both between the complete TLI group (17 patients including three non-randomised) and the sham group and between the 14 randomised patients given TLI and the sham group. The data have been analysed taking into account age, sex, and pattern of disease (relapsing progressive or primary progressive) as well as treatment group. For the major outcome criterion (EDSS score) the sham treated group deteriorated by 0.25 grades per year more than the treated (all) group $(0.26$ grades more than randomised only) but this result is far from statistical significance. For the functional scale (and for its three subscales of walking, activities of daily living and transferring) there was virtually no difference between the rates of change in the sham and TLI groups. On measures of walking speed, disability (incapacity status score), and handicap (environmental status score) differences in rates of change were all small and non significant. In the Kurtzke functional systems scales there seemed to be a small but significant difference in the rate of decline of the score for bladder dysfunction that favoured the treated group (all $p=0.04$, randomised only $p=0.02$ ). There was a similar but non-significant trend in the visual function subscale again favouring the treated group (all $p=0.07$, randomised only $p=$ $0 \cdot 06$ ). One sham treated patient died of multiple sclerosis before the six month follow up and those scales that did not score death were subsequently set to their maximum "worst" score; removing these scores did not materially influence the results.

\section{MRI RESULTS}

These results include all studies undertaken in treatment and sham groups before and at six, 12, 18, and 24 months after treatment. Two patients in the sham group did not have 12 month studies (one death and one unable to attend) but one was imaged at six months. Two treated patients could not attend at six months but had imaging at 12 months. Table 3 shows the mean (SE) numbers of new or enlarged lesions, those that were decreased or gone and the net change in lesion count for successive six month follow up periods. Table 4 shows the mean (SE) differences in the net lesion change between the TLI and sham treated groups (with $95 \%$ confidence intervals $(95 \% \mathrm{CIs}))$. There was a consistent tendency for the TLI group (all or just randomised) to show a net loss of lesions up to 18 months of follow up whereas the sham group showed a small net gain (table 3 ). The difference between treatment groups approaches statistical significance at six months of follow up (table 4).

The gains and losses of MRI lesions from 
Table 3 Changes in MRI lesion counts

\begin{tabular}{|c|c|c|c|}
\hline & \multicolumn{3}{|c|}{ Mean (SE) lesion count changes } \\
\hline & All TLI (17) & $\begin{array}{l}\text { Randomised } \\
T L I(n=14)\end{array}$ & Sham (10) \\
\hline $\begin{array}{l}\text { 0-6 months: } \\
\text { No } \\
\text { New or enlarged } \\
\text { Decreased or gone } \\
\text { Change }\end{array}$ & $\begin{array}{l}15 \\
1.6(0.5) \\
-3.3(1 \cdot 1) \\
-1.7(1.3)\end{array}$ & $\begin{array}{l}14 \\
1.7(0.5) \\
-2.6(0.9) \\
-0.9(1.1)\end{array}$ & $\begin{array}{r}9 \\
3.2(0.7) \\
-1.3(0.6) \\
1.9(0.9)\end{array}$ \\
\hline $\begin{array}{l}\text { 6-12 months: } \\
\text { No } \\
\text { New or enlarged } \\
\text { Decreased or gone } \\
\text { Change }\end{array}$ & $\begin{array}{l}15 \\
1.4(0 \cdot 6) \\
-2 \cdot 4(1 \cdot 2) \\
-1 \cdot 0(1 \cdot 4)\end{array}$ & $\begin{array}{r}14 \\
1.2(0.6) \\
-0.9(0.4) \\
0.3(0.7)\end{array}$ & $\begin{array}{l}8 \\
2.1(0.7) \\
-1.9(0.8) \\
0.3(0.5)\end{array}$ \\
\hline $\begin{array}{l}\text { 12-18 months: } \\
\text { No } \\
\text { New or enlarged } \\
\text { Deceased or gone } \\
\text { Change }\end{array}$ & $\begin{array}{l}13 \\
0.6(0.5) \\
-1.3(0.5) \\
-0.7(0.7)\end{array}$ & $\begin{array}{l}11 \\
0.6(0.5) \\
-1.4(0.6) \\
-0.7(0.9)\end{array}$ & $\begin{array}{r}8 \\
2.0(0.6) \\
-1 \cdot 1(0.6) \\
0.9(0.9)\end{array}$ \\
\hline $\begin{array}{l}\text { 18-24 months: } \\
\text { No } \\
\text { New or enlarged } \\
\text { Decreased or gone } \\
\text { Change }\end{array}$ & $\begin{array}{l}12 \\
1.2(0.4) \\
-0.5(0.2) \\
0.6(0.4)\end{array}$ & $\begin{array}{l}10 \\
1.2(0.5) \\
-0.5(0.3) \\
0.7(0.5)\end{array}$ & $\begin{aligned} & 8 \\
& 1.8(1.0) \\
&-0.8(0.5) \\
& 1.0(1.2)\end{aligned}$ \\
\hline
\end{tabular}

Table 4 Difference between net change of lesions in TLI and sham groups

\begin{tabular}{|c|c|c|c|c|}
\hline & \multicolumn{4}{|c|}{ Difference between change of lesions } \\
\hline & \multicolumn{2}{|c|}{$T L I$ (all) 一sham group } & \multicolumn{2}{|c|}{ TLI (randomised)—sham group } \\
\hline & Mean $(S E)$ & $95 \% C I$ & Mean (SE) & $95 \% C I$ \\
\hline $\begin{array}{l}0-6 \text { months } \\
6-12 \text { months } \\
12-18 \text { months } \\
18-24 \text { months }\end{array}$ & $\begin{array}{l}-3.6(1.9) \\
-1.3(2.8) \\
-1.5(1.2) \\
-0.4(1.2)\end{array}$ & $\begin{array}{l}-7 \cdot 4 \text { to } 0.3 \\
-5.6 \text { to } 3 \cdot 1 \\
-4 \cdot 1 \text { to } 1 \cdot 0 \\
-2 \cdot 8 \text { to } 2 \cdot 1\end{array}$ & $\begin{array}{r}-2.8(1.6) \\
0.0(1.1) \\
-1.6(1.3) \\
-0.3(1.2)\end{array}$ & $\begin{array}{l}-6.0 \text { to } 0.5 \\
-2.2 \text { to } 2.2 \\
-4.3 \text { to } 1.1 \\
-2.9 \text { to } 2.3\end{array}$ \\
\hline
\end{tabular}

baseline and at six, 12, 18 and 24 months were used to construct lesion scores at each time point (fig 4). On the relatively undemanding assumption that variation about the trend at one point is independent of that at other points the individual sequences can then be modelled and compared. This approach was used to assess the effect of treatment by testing whether there was any systematic difference in the pattern of change over time between the two treatment groups.

The trends over time in the lesion scores were analysed by assuming that the counts at any point came from a normal distribution and fitting trends to each patient. The trends were constrained to follow the same average

Figure 4 Cumulative change (gains and losses) in MRI lesion count from baseline scan for TLI and sham treated groups (each symbol type represents a patient).
Table 5 Psychometry

\begin{tabular}{lll}
\hline & $\begin{array}{l}T L I \\
(n=11)\end{array}$ & $\begin{array}{l}\text { Sham } \\
(n=5)\end{array}$ \\
\hline Wisconsin time(s) (mean (SD)): & $449(273)$ & $716(356)$ \\
$\quad$ Pretreatment & $422(271)$ & $427(163)$ \\
12 months & $482(275)$ & $340(85)^{\star}$ \\
24 months & & \\
Wisconsin correct categories & & \\
(mean (sd)): & & \\
Pretreatment & $4 \cdot 3(2 \cdot 1)$ & $4 \cdot 6(1 \cdot 9)$ \\
12 months & $3 \cdot 8(2 \cdot 5)$ & $6 \cdot 0(0 \cdot 0)$ \\
24 months & $3 \cdot 5(2 \cdot 6)$ & $6 \cdot 0(0 \cdot 0)^{\star}$ \\
Wisconsin No of errors & & \\
(mean (SD)): & & \\
Pretreatment & $9 \cdot 6(8 \cdot 7)$ & $9 \cdot 4(4 \cdot 8)$ \\
24 months & $11 \cdot 2(9 \cdot 3)$ & $6 \cdot 8(8 \cdot 5)$ \\
\hline
\end{tabular}

${ }^{\star} \mathrm{p}<0.05$.

pattern within each treatment group while allowing the pattern to vary between treatment groups. A plot of the residuals from the non-linear trend model showed that, although there was some evidence of skewness, the underlying variation was adequately normal. With or without the three patients who were not randomly allocated to treatment it was clear that straight line models were adequate to represent trends in the data. The gradients (lesion score/time) of the placebo and treatment groups were significantly $(p<0.01)$ different. Lesion scores in the sham treated group tended to increase compared with those in the treated group, which tended to decrease. No effect of the initial disease pattern (relapsing progressive or primary progressive) was seen $(p=0.39)$.

\section{PSYCHOMETRIC ASSESSMENTS}

Complete two year follow up data sets were obtained for only 11 treated and five sham treated patients. There were no significant differences over time in the changes between the two treatment groups with respect to the WAIS verbal subtests, the speed tests, Raven's matrices, and verbal and visual recognition memory tests. On the Wisconsin card sorting test (table 5) two of the three performance measures showed a significant difference that favoured the sham treated group, who seemed to show some improvement over the follow up period.

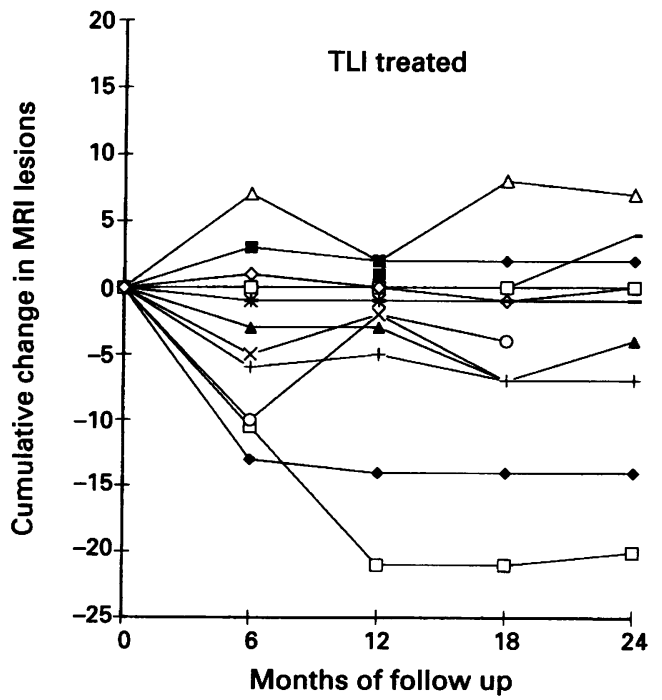


Table 6 Side effects

\begin{tabular}{|c|c|c|c|}
\hline Treatment group & Treated (all) & $\begin{array}{l}\text { Treated } \\
\text { (randomised) }\end{array}$ & Sham \\
\hline $\begin{array}{l}\text { No } \\
\text { Acute side effects: }\end{array}$ & 17 (8 women) & 14 (6 women) & 10 ( 3 women) \\
\hline $\begin{array}{l}\text { Nausea } \\
\text { Vomiting } \\
\text { Change of bowel } \\
\text { habit }\end{array}$ & $\begin{array}{l}8 \\
6 \\
7\end{array}$ & $\begin{array}{l}8 \\
5 \\
6\end{array}$ & $\begin{array}{l}2 \\
1 \\
3\end{array}$ \\
\hline Tiredness & 10 & 8 & 4 \\
\hline $\begin{array}{l}\text { Later complications: } \\
\text { Deaths } \\
\text { Amenorrhoea } \\
\text { No having } \\
\text { infections }\end{array}$ & $\begin{array}{l}1 \\
6 \\
14\end{array}$ (28 infections) & $\begin{array}{l}1 \\
4 \\
11 \text { (25 infections) }\end{array}$ & $\begin{array}{l}2 \\
0 \\
4 \text { (6 infections) }\end{array}$ \\
\hline $\begin{array}{l}\text { No having } \\
\text { antibiotics }\end{array}$ & 12 (28 courses) & 9 (25 courses) & 3 (4 courses) \\
\hline $\begin{array}{l}\text { Body hair loss } \\
\text { Other }\end{array}$ & $\begin{array}{l}11 \\
1 \text { Hepatitis } \\
1 \text { Dermatitis } \\
1 \text { Seizure }\end{array}$ & $\begin{array}{l}11 \\
1 \text { Hepatitis } \\
1 \text { Dermatitis } \\
1 \text { Seizure }\end{array}$ & $\begin{array}{l}0 \\
1 \text { Oesophagitis } \\
1 \text { Depression } \\
1 \text { Hysterectomy }\end{array}$ \\
\hline
\end{tabular}

SIDE EFFECTS (TABLE 6)

A questionnaire concerning adverse events of treatment was presented after completion of treatment: enquiry was made at each follow up visit and by letter to patient and general practitioner at annual follow up subsequently (results include data up to February 1993). Amenorrhoea was the principle side effect occurring in all women at risk (two patients had previously had a hysterectomy): all patients were referred to a gynaecologist for assessment and were offered hormone replacement therapy if appropriate. Patients given TLI had more infections and courses of antibiotics than sham treated patients $\chi^{2}$ test with continuity correction 7.2 and 6.0 respectively, $p<0.02$ ). There was a significant excess of patients noticing body hair loss in the treated group $\left(\chi^{2}\right.$ test $\left.11.51, \mathrm{p}<0.001\right)$.

\section{Discussion}

In this study we have treated a highly selected small group of patients with chronic progressive disability due to multiple sclerosis from a large local population of patients with multiple sclerosis (about 7000 in the Greater London area). The patients had significant disability that had substantially worsened in the year before trial entry as measured on the Kurtzke scale. Although it has recently been noted that there may be differences in MRI appearances of primary progressive multiple sclerosis and secondary progressive disease $\mathrm{e}^{33}$ we found no difference in mean lesion load between these two groups in this small prospectively classified study group before treatment (table 7). Nevertheless the imbalance in the make up of the two treatment groups for disease type has been allowed for

Table 7 Data relating pattern of multiple sclerosis with age, disability, and lesion load

\begin{tabular}{llc}
\hline & $\begin{array}{l}\text { Relapsing }\left(2^{\circ}\right) \\
\text { progressive } \\
(n=21)\end{array}$ & $\begin{array}{l}\text { Primary } \\
\text { progressive } \\
(n=6)\end{array}$ \\
\hline Mean age (SD) & $37 \cdot 1(5 \cdot 6)$ & $39 \cdot 1(9 \cdot 8)$ \\
Mean EDSS (SD) & $5 \cdot 9(1 \cdot 2)$ & $6 \cdot 0(0 \cdot 7)$ \\
MRI lesion load & $92 \cdot 3(44 \cdot 5)$ & $116(56 \cdot 0)$ \\
\hline
\end{tabular}

in the analysis of clinical data. There was no correlation between lesion load and pretreatment expanded Kurtzke disability status score $\left(r^{2}=0.08\right)$.

The treatment protocol used was similar to that used in the United States trial. ${ }^{1934}$ It followed the same modified regimen and treatment was administered over a similar total period (United Kingdom study mean 37, United States 39 days): the calculated spinal cord dose was a little higher at $1265 \mathrm{cGy}$ in our study compared to 1050 cGy in the United States. In the current study the absolute lymphocyte count had fallen by $83 \%$ of the pretreatment value at the end of treatment and by $63 \%$ one month later, the last figure comparing with a $73 \%$ decline noted previously. ${ }^{33}$ At one year after treatment $94 \%$ of patients (all but one) had lymphocyte counts below the pretreatment values and $41 \%$ had counts $=\leqslant 900 / \mathrm{mm}^{3}$ compared with figures of $75 \%$ and $50 \%$ respectively in the United States study. The pattern and degree of change of $\mathrm{CD4}^{+}$and $\mathrm{CD}^{+} \mathrm{lym}$ phocytes and the $\mathrm{CD}^{+}: \mathrm{CD}^{+}$ratio were similar in the two studies. We would thus judge that TLI had had a generally similar biological effect. It has been noted in patients with rheumatoid disease that similar radiological effects on the lymphocyte count may be obtained by 2000 cGy excluding the spleen. ${ }^{15}$

Our patients were on average six years younger in the treated group and 4.7 years younger in the sham group, but of similar sex distribution to those in the United States study. Although the standard EDSS was not used in the United States study their disability scale had some similar features and it is likely that our patients were slightly less disabled than theirs at entry: this is reinforced by their average functional scale scores at entry of 5.9 and 5.6 (treated and sham) compared with our entry scores on this scale of 5.0 and 4.0 (treated and sham). It is not possible to judge from the United States study to what extent patients had declined in disability in the year before entry.

Although patients who developed amenorrhoea or hair loss often guessed correctly that they had received active treatment when asked at six months five of nine sham treated patients alive thought that they had also received active treatment. It was thus only partially the case that patients were blind to the treatment which they had received. The clinical assessor and psychologist examined and tested the patients clothed, however, and did not discuss treatment or side effects. The MRI scans were assessed by a radiologist (IFM) who was not involved in the technical execution of the scans and who did not have access to either clinical details or treatment codes.

Treated patients had fewer new or enlarged MRI brain lesions with more being smaller or disappearing than the sham treated group based on a trend analysis over the whole follow up period. The mean rates of change in lesion score were significantly different in the treated and control group indi- 
cating that overall there had been a net loss of lesions in the treated group and a slight gain in the sham group. Allowing for disease pattern did not affect the results. It is clear, however, that lesion activity as reflected by unenhanced MRI was only partially suppressed by treatment as 14 out of 17 treated patients developed at least some new or enlarging lesions during follow up. It is possible that the greater number of lesions disappearing or getting smaller in the treated group, particularly during the first six months, was due to there having been more active lesions in that group on the baseline images. This possibility cannot be excluded without having had either more than one pretreatment study or having a gadolinium enhanced study in all patients. More frequent MRI in the first year of the study, particularly if combined with gadolinium enhancement, ${ }^{35}$ might have also allowed the recognition of turnover of a greater number of lesions and thereby increased the sensitivity of the technique for determining a treatment effect. Furthermore, we did not undertake routine imaging of the spinal cord: this was, at the time, difficult to quantify technically and in this study the cord, unlike the brain, received a significant radiation dose that may have had a direct effect on lesion size and intensity.

Despite the slight radiological benefit, we found little evidence of clinical benefit from TLI as indicated by the mean rates of progression of disability or other clinical indices. In the United States trial benefit was evident on the functional scale but less obvious on the disability scale used. We found that there was a close correlation between the expanded Kurtzke disability status score and the functional scale at any particular time point (for example, Spearman coefficient $0.95,95 \% \mathrm{CI}$ 0.90 to 0.98 for pretreatment scores and $0 \cdot 87,95 \%$ CI 0.74 to 0.94 at six months after treatment). On neither scale, however, was there any indication of a significant benefit from treatment whether or not the three nonrandomised patients were excluded and after making allowance for age, sex, and disease pattern. Of the subscales used only the functional status.scales for bladder and visual function seemed to show benefit: this was not reflected in the visual analogue scales filled in by the patients and may have occurred by chance.

The target of recruiting 56 patients proved not to be possible in a reasonable time despite a large base population. The mean actual decline in EDSS of the 24 randomised patients in the study was 0.79 (SD 1.05) and a post hoc calculation of the power of the study to detect a difference of this order between treated and sham groups was 0.65 . Thus there is a possibility of 0.35 of a false negative result. Nevertheless we infer from the overall pattern of clinical results that it is unlikely that a major clinical benefit has been missed. In particular the changes on the functional scale, which was the main positive outcome feature in the United States study, show no trend in favour of the treatment group.
We categorised TLI treated patients into those with lymphocyte counts $>$ or $\leqslant 850 / \mathrm{mm}^{3}$ in the three months after the completion of treatment and into those improving or worsening by one full grade on the EDSS between pretreatment and six months and six to 12 months but found no evidence that those who deteriorated least had the lower lymphocyte counts. This contrasts with the finding that patients with counts $<900 / \mathrm{mm}^{3}$ benefited more than those with higher counts in a group of 27 patients who received treatment (three openly). ${ }^{36} \mathrm{We}$ did, however, note an association between lymphocyte counts $\leqslant 850 / \mathrm{mm}^{3}$ and initial MRI lesion load: those with the lower lymphocyte counts had a mean lesion load of $65.5(18.8)$ compared with those with higher counts who had a load of $123.4(56.4)$ and the difference was significant $(t=-2.22, p=0.04)$. The relation between disease burden (one measure of which might be lesion load) and the response to immunosuppression of this type thus requires further investigation. No association was found between clinical progression and any of the lymphocyte subset data.

Changes in psychometric measures were small over the two year follow up in the 16 patients who were fully assessed at one and two years. Although the pattern of test results showed some abnormalities (full results not shown) these changed little with time. A difference emerged between the treated and sham treated groups in the time needed to complete the Wisconsin card sorting test and the number of correct categories achieved (table 5): on first testing the sham group took longer than the treated group, at one year the same time, and at two years was quicker to complete the task. The sham group also achieved significantly more correct categories. Previous studies have indicated the importance of speed of information processing in multiple sclerosis. ${ }^{37}$ In this respect the treated group seemed to be more impaired than the sham treated group at two years of follow up. The samples (11/14 randomised TLI and 5/10 sham), however, are small and data acquisition was more complete in the treated group-a possible source of bias. The data emphasise the need for psychometric evaluation in future long term trials of this type.

Overall, side effects in the study were associated with active treatment but have not so far caused excess mortality. Amenorrhea was a significant although expected event that would limit the usefulness of this treatment were it to be of benefit: a recent study has emphasised the morbidity of ovarian failure after total body irradiation for leukaemia. ${ }^{38}$ The increased risk of infection is both expected and relevant. In the United States study, currently there have been six deaths in 51 patients receiving TLI (12\%) $v$ three deaths in 21 patients receiving sham irradiation (14\%) (SD Cook, personal communication). The original reported excess of deaths in their treatment group was associated with either advanced multiple sclerosis or increased susceptibility to and poorer progno- 
sis from infection..$^{20}$ On average our patients were slightly less disabled than those in the United States study but our average follow up remains shorter than that of Cook et al where most deaths occurred between 42 and 54 months after therapy. ${ }^{20} \mathrm{We}$ would support the view that the prognosis of infection in a severely disabled patient with multiple sclerosis may be adversely affected by previous lymphoid irradiation. It is possible that avoidance of splenic irradiation might reduce this risk without a reduction of efficacy in terms of depression of lymphocyte counts. ${ }^{15}$

So far during follow up we have not encountered new malignant disease (previous malignant disease excluded patients from entry). Evidence of the magnitude of this risk comes from long term follow up of patients with Hodgkin's disease treated with TLI and or chemotherapy. In a study of 2846 patients first treated from 1970-87 for Hodgkin's disease the relative risk of leukaemia appeared not to be appreciably increased by TLI alone whereas extensive radiotherapy was associated with a relative risk of $1.9(95 \%$ CI 1.0 to $3 \cdot 1)$ for all solid tumours other than lung cancer and $3.9(1.7$ to 7.8$)$ for lung cancer. ${ }^{39}$ The dose in that study was typically greater $(3500-4000 \mathrm{cGy})$ than in the present protocol. Nevertheless, even relatively low risks need to be considered carefully in administering such treatment to patients who may be young, who may receive at certain times other immunosuppressive regimes, and in whom the individual prognosis may be uncertain.

In conclusion we have effectively produced prolonged immunosuppression in a group of patients with progressive disability from multiple sclerosis. Although there is some evidence for a modest effect on the rate of accrual of brain lesions clear clinical benefit was not detectable. There are substantial practical and theoretical grounds for exercising great caution in the administration of TLI to patients with multiple sclerosis, not least being the increased risks of amenorrhea, infection, and long term incidence of solid tumour. In our view possible clinical benefits demonstrated in the United States study ${ }^{19}$ together with slight radiological benefit in the present study, although of theoretical interest, are outweighed by the excess morbidity, possible mortality, and lack of reproducible efficacy and the technique cannot be recommended for routine clinical practice. TLI fits with a number of other non-specific immunosuppressive regimes in producing small or no clinical benefits at some inconvenience and risk to patients with multiple sclerosis. ${ }^{4-1019} \mathrm{It}$ is possible that TLI (perhaps without splenic irradiation) will be an effective method of inducing immunosuppression in multiple sclerosis, which might then be followed by longer term therapy with another immunosuppressive agent. Clinical trials of better targeted long term regimes, based on more detailed understanding of the mechanisms of the disease and monitored with frequent $\mathrm{MRI}^{34}{ }^{40}$ as well as clinical indices, still offer the surest way forward.
The study was supported by the Multiple Sclerosis Society of Great Britain. Our thanks are due to the patients who participated in this study, to the physicians who referred them and
to Dr P Rudge for his advice. Dr AG Kermode, Dr BD Youl, and Dr T Yousry assisted with MRI data acquisition and analysis. We also thank Professor EK Warrington, Dr JR Willison, and Mrs M Bernstein for help with clinical psychology and Professor D Dumonde, Dr R Jenkins, Sylvia Young, and Stephanie Mayall for help with the immunological and Steph

1 Calder V, Owen S, Watson C, Feldmann M, Davison A. MS: a localised immune disease of the central nervous system. Immunol Today 1989;10:99-103.

2 Hafler DA, Weiner HL. MS: a CNS and systemic autoimmune disease. Immunol Today 1989;10:104-7.

3 Raine CS. Multiple Sclerosis: a pivotal role for the T cell in lesion development. Neuropathol Appl Neurobiol 1991;17:265-74.

4 Hauser SL, Dawson DM, Lehrich JR, et al. Intensive immunosuppression in progressive multiple sclerosis. A randomised three-arm study of high dose intravenous cyclophosphamide, plasma exchange, and ACTH. $N$ cyclophosphamide, plasma

5 Khatri BO, McQuillen MP, Harrington GJ, Schmoll D, Hoffman RG. Chronic progressive multiple sclerosis: double blind controlled study of plasmapheresis in patients taking immunosuppressive drugs. Neurology 1985;35:312-9.

6 British and Dutch Multiple Sclerosis Azathioprine Trial Group. Double-masked trial of azathioprine in multiple sclerosis. Lancet 1988;ii:179-83.

7 Rudge P, Koetsier JC, Mertin J, et al. Randomised controlled trial of cyclosporin in multiple sclerosis. $f \mathrm{Neurol}$ Neurosurg Psychiatry 1989;52:559-65.

8 Bornstein MB, Miller A, Slagle S, et al. A placebo-controlled, double-blind, randomised, two-center, pilot trial of Cop 1 in chronic progressive multiple sclerosis. Neurology 1991;41:533-9.

9 The Canadian Cooperative Multiple Sclerosis Study Group. The Canadian cooperative trial of cyclophosphamide and plasma exchange in progressive multiple sclerosis. Lancet 1991;337:441-6.

10 Yudkin PL, Ellison GW, Ghezzi A, et al. Overview of azahioprine in multiple sclerosis. Lancet 1991;338:1051-5.

11 Slavin S. Total lymphoid irradiation. Immunol Today 1987;8:88-92.

12 Kotzin BL, Strober S, Engleman EG, et al. Treatment of intractable rheumatoid arthritis with total lymphoid irradiation. N Engl F Med 1981;305:969-76.

13 Trentham DE, Belli JA, Anderson RJ, et al. Clinical and immunologic effects of fractionated total lymphoid irradiation in refractory rheumatoid arthritis. $N$ Engl $f$ Med 1981;305:976-82.

14 Strober S, Tanay A, Field E, et al. Efficacy of total lymphoid irradiation in intractable rheumatoid arthritis. phoid irradiation in intractable

15 Hanly JG, Hassan J, Moriarty $M$, et al. Lymphoid irradiation in intractable rheumatoid arthritis: a double blind radomised study comparing $750 \mathrm{rad}$ treatment with 2000 rad treatment. Arthritis Rheum 1986;29: 16-25.

16 Strober S, Farinas C, Field EH, et al. Treatment of lupus nephritis with total lymphoid irradiation: observations during a 12-79 month follow up period. Arthritis Rheum 1988;31:850-8.

17 Najarian JS, Ferguson RM, Sutherland DER, et al. Fractionated total lymphoid irradiation as preparative immunosuppression in high-risk renal as prlantation: clinical and immunologic studies. Ann Surg 1982;196: 442-51.

18 Hafstein MP, Devereux C, Troiano R, et al. Total lymphoid irradiation in chronic progressive multiple sclerophoid irradiation in chronic progressive mul
sis. Ann N Y Acad Sci 1984;436397-409.

19 Cook SD, Devereux C, Troiano $R$, et al. Effect of total lymphoid irradiation in chronic progressive multiple sclerosis. Lancet 1986;i:1405-9.

20 Cook SD, Troiano R, Zito G, Rohowsky-Kochan C, Sheffit A, Dowling PC. Deaths after total lymphoid irradiation for multiple sclerosis. Lancet 1989;ii:277-8

21 Wiles CM, Sawle G, Gilbert L, Joannides T. Total lymphoid irradiation in multiple sclerosis: a preliminary report. $₹$ Neurol Neurosurg Psychiatry 1990;53:817.

22 Poser CM, Paty DW, Scheinberg L, et al. New diagnostic criteria for multiple sclerosis: guidelines for research proposals. Ann Neurol 1983;13:227-31.

23 Kroposals. Ann Neurol 1983;13:227-31. sclerosis: an expanded disability scale (EDSS). Neuro$\log y 1983 ; 33: 1444-52$

24 International Federation of Multiple Sclerosis Societies' minimal record of disability for multiple sclerosis. Interview protocol for incapacity status scale and environmental status scale. Acta Neurol Scand 1984;70(suppl 101):191-217.

25 Payne CD. The GLIM 3.77 release manual. Oxford: NAG 1985

26 Nelson HE. National adult reading test: manual. Windsor: NFER-Nelson, 1982.

27 Willison JR. Neuropsychological investigations of a set of mental speed tests. London: University of London, 1988. (PhD Thesis.)

28 Warrington EK. Recognition memory tests. Windsor: NFER-Nelson, 1984. 
29 Baxter D. Raven progressive matrices (short version-20). London, The National Hospital for Nervous Diseases, 1985. 30 Nelson HE. A modified card sorting test sensitive to frontal lobe defects. Cortex 1975;12:313-24.

31 Ormerod IEC, Miller DH, McDonald WI, et al. The role of NMR imaging in the assessment of multiple sclerosis and isolated neurological lesions: a quantitative study. Brain 1987;110:1579-616.

32 MacManus DG, Kermode AG, Tofts PS. $A$ repositioning technique for cerebral magnetic resonance imaging of patients technique for cerebral magnetic resonance imaging of patients with multiple sclerosis. Berkeley, CA, Book of abstracts,
Society of Magnetic Resonance in Medicine, 1989;2:

33 Thompson AJ, Kermode AG, MacManus DG, et al. Patterns of disease activity in multiple sclerosis: clinical and magnetic resonance imaging study. $B M F 1990 ; 300$ 631-4.

34 Devereux CK, Vidaver R, Hafstein MP, et al. Total lymphoid irradiation for multiple sclerosis. Int $f$ Radiat Oncol Biol Phys 1988;14:197-203.

35 Miller DH, Barkhof F, Berry I, Kappos L, Scotti G, Thompson AJ. Magnetic resonance imaging in monitor-
Action Guidelines. F Neurol Neurosurg Psychiatry 1991; 54:683-8.

36 Devereux C, Troiano R, Zito G, et al. Effect of total lymphoid irradiation on functional status in chronic multiple sclerosis: importance of lymphopenia early after treatment-the pros. Neurology 1988;38(suppl 2): 32-7.

37 Callanan-Kelsey MM. Cognitive impairment in multiple sclerosis. Clinical and NMR correlates. $\mathrm{PhD}$ thesis, Sclerosis. Clinical and NMR

38 Cust MP, Whitehead MI, Powles R, Hunter M, Milliken $S$. Consequences and treatment of ovarian failure after total body irradiation for leukaemia. $B M \mathcal{F}$ 1989;299: total body

39 Sverdlow AJ, Douglas AJ, Hudson GV, Hudson BV, Bennett MH, MacLennan KA. Risk of second primary cancers after Hodgkin's disease by type of treatment: analysis of 2846 patients in the British Lymphoma Investigation. $B M F$ 1992;304:1137-43.

40 McFarland HF, Frank JA, Albert PS, et al. Using gadolinium-enhanced magnetic resonance imaging lesions to monitor disease activity in multiple sclerosis. Ann Neurol 1992;32:758-66. 